\begin{tabular}{|l|l|l|l|}
\hline Variable & Baseline (mean) & $\begin{array}{l}\text { Post-intervention } \\
\text { (mean) }\end{array}$ & Mean difference; 95\% Cl \\
\hline $\begin{array}{l}\text { Time to fall asleep } \\
\text { (mins) }\end{array}$ & 99.26 & 20.38 & $\begin{array}{l}\mathrm{MD} 78.88 ; 95 \% \mathrm{Cl} 65.46-92.29, \\
\mathrm{p}<0.05\end{array}$ \\
\hline $\begin{array}{l}\text { Number of nights } \\
\text { wake per week }\end{array}$ & 3.92 & 0.85 & $\begin{array}{l}\mathrm{MD} 3.08 ; 95 \% \mathrm{Cl} 2.51-3.64, \\
\mathrm{p}<0.05\end{array}$ \\
\hline $\begin{array}{l}\text { Number of } \\
\text { awakenings per night }\end{array}$ & 1.88 & 0.45 & $\begin{array}{l}\mathrm{MD} 1.42 ; 95 \% \mathrm{Cl} \text { 0.96-1.88, } \\
\mathrm{p}<0.05\end{array}$ \\
\hline $\begin{array}{l}\text { Time awake during } \\
\text { night (mins) }\end{array}$ & 66.78 & 5.75 & $\begin{array}{l}\mathrm{MD} 60.39 ; 95 \% \mathrm{Cl} \text { 42.36-78.42, } \\
\mathrm{p}<0.05\end{array}$ \\
\hline $\begin{array}{l}\text { Number of hours } \\
\text { sleep (hrs) }\end{array}$ & 7.98 & 10.18 & $\begin{array}{l}\mathrm{MD} 2.20 ; 95 \% \mathrm{Cl} 1.82-2.57 ; \\
\mathrm{p}<0.05\end{array}$ \\
\hline
\end{tabular}

Abstract 7 Figure 1 Sleep measures before and after the sleep intervention $(n=104)$. Improvement in all measures was statistically significant $(p<$ 0.05)

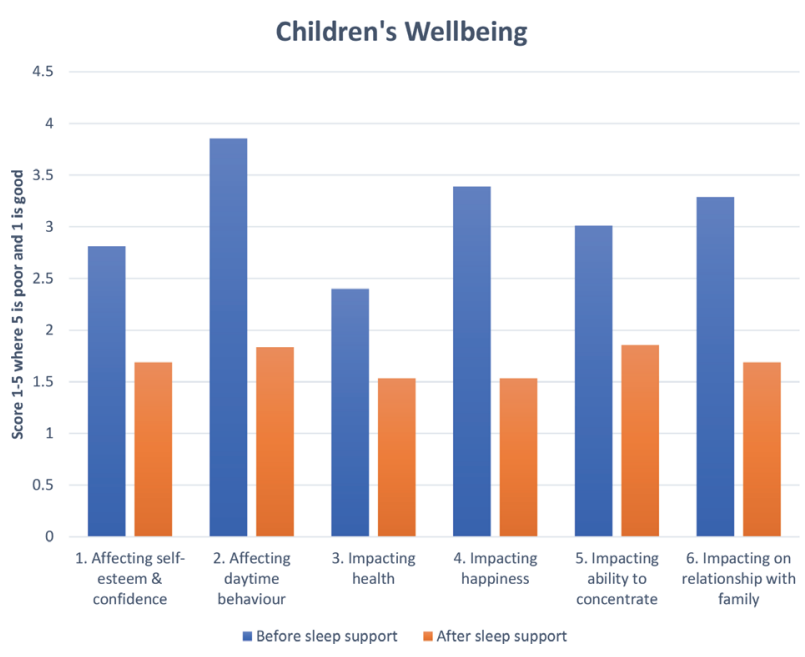

Abstract 7 Figure 2 Children's individual wellbeing measures and mean total wellbeing score before and after the sleep intervention $(n=92)$. Each question was rated on a scale of 1-5 where 1 was good and 5 was poor. All measures showed significant improvement $(\mathrm{p}<$ $0.05)$

to-one sleep service delivered via on-line clinics by community sleep practitioners in the UK.

Methods The study was an observational pre- and post- evaluation in a 12-month period. The intervention is derived from the behavioural aspects of Cognitive Behavioural Therapy for insomnia. The evaluation was questionnaire-based and assessed sleep parameters and wellbeing.

Results 104 parents returned completed questionnaires. Average sleep onset was 1 hour, 39 minutes pre-intervention and 20 minutes post-intervention. Average nights that the child woke per week was 3.9 pre-intervention and 0.9 post-intervention; night awakenings fell from 1.9 to 0.5 and time awake after sleep onset fell from 66. 8 minutes to 5.8 minutes. The average time slept asleep per night was 8.0 hours pre-intervention and 10.2 hours post-intervention. Improvement in all sleep measures was statistically significant $(\mathrm{p}<0.05)$ see figure 1 . All measures of parental and children's wellbeing improved significantly $(p<0.05)$ except for their perceived ability to drive $(p=0.07)$, see figure 2 for children's wellbeing scores. $100 \%$ parents stated that they would recommend the sleep support and 20\% already had.

Discussion We believe that this is the first report of a videobased clinic developed for children's behavioural insomnia during the COVID-19 pandemic in the UK.

The COVID-19 pandemic has accelerated the evolution of telehealth and, in the case of children's sleep clinics, has provided a mode of intervention delivery that is as effective as face-to-face delivery, acceptable and accessible.

\section{INVESTIGATING THE CLINICAL COURSE OF CHILDREN WITH CENTRAL SLEEP APNOEA SEEN AT SHEFFIELD CHILDREN'S HOSPITAL: A RETROSPECTIVE DESCRIPTIVE ANALYSIS}

${ }^{1}$ Lucy Pinder* ${ }^{2}$ Kelechi Ugonna, ${ }^{2}$ Ruth N Kingshott. ${ }^{1}$ The University of Sheffield, Sheffield, UKi ${ }^{2}$ Sheffield Children's Hospital, Sheffield, UK

\subsection{6/bmiresp-2021-bssconf.7}

Introduction Central sleep apnoea (CSA) is an uncommon paediatric syndrome characterised by recurrent cessations of ventilatory effort related to a lack of central drive to breathe during sleep. Literature describing the expected clinical course of CSA is limited and there are no guidelines on appropriate management. The study aimed to follow children with CSA from presentation to final outcome and investigate the factors associated with the choices for management of these patients. Methods A retrospective analysis of medical records of children with CSA seen at Sheffield Children's Hospital (SCH) over 10 years was conducted $(n=30)$. Children with a diagnosis of CSA or polysomnography (PSG) findings that would be classified as CSA under current practices (an apnoea-hypopnoea index (AHI) of $\geq 5 /$ hour or significant physiologic changes related to central apnoeas) were eligible for inclusion. Data was collected on demographics, co-morbidities, 


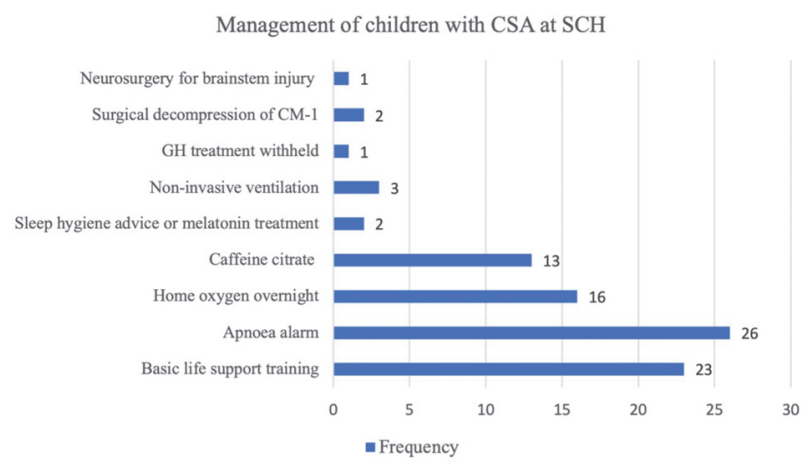

Abstract 9 Figure 1 Bar chart showing the frequency of different managements seen in children with CSA at SCH

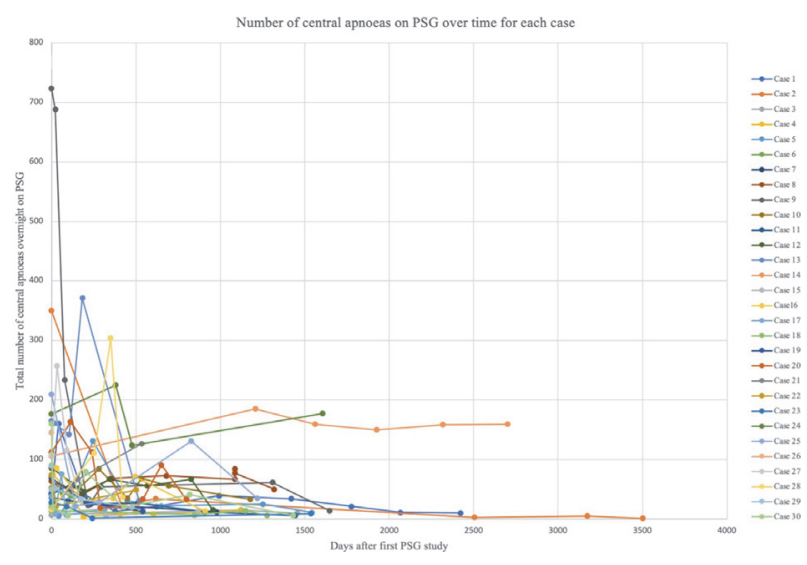

Abstract 9 Figure 2 Number of central apnoeas recorded on PSG over time for each child with CSA seen at $\mathrm{SCH}$, demonstrating a mean decrease of 15.42 central apnoeas from first to last PSG $(p=0.000)$

presentation, clinical events, diagnosis, investigations (including PSG and oximetry results), management (figure 1), factors related to management choices, and outcomes.

Results $43.3 \%$ presented with a 'brief resolved unexplained event' (11 resuscitated). The most common age at presentation was 8 -weeks $(n=8) .20 \%$ were being safeguarded. The most common co-morbidities $(n=9)$ were reflux and heart murmurs. The number of central apnoeas, AHI, and $3 \%$ desaturation index were shown to significantly improve from the first to last PSG ( $\overline{\mathrm{x}}$ improvement $=15.42, \mathrm{p}=0.000 ; \overline{\mathrm{x}}$ improvement $=15.80, \quad \mathrm{p}=0.002 ; \quad \overline{\mathrm{x}} \quad$ improvement $=15.82$, $\mathrm{p}=0.005$ respectively) (figure 2 ). $8 / 30$ patients were discharged from the sleep service ( $1 / 8$ deceased due to CSA). Children with parents reported to be anxious remained in the service for significantly longer than children without $(\mathrm{x} 2=3.855, \mathrm{p}=0.05)$.
Discussion PSG results demonstrated that this is a significant syndrome with risk of mortality, however the natural clinical course of paediatric CSA is improvement with time. Parental anxiety significantly increases the length of management time. This is the first study to document the death of a child primarily due to CSA.

\section{CONTINUOUS POSITIVE AIRWAYS PRESSURE (CPAP) - DRIVE THRU COLLECTION CLINIC (DTCC)}

Karena Cranstone*, Mark Unstead, Lauren Kimberley, Emily Seaman, Jessica Swan, Manisha Perera, Bethany Swaffield, Natalie Wilson, Harry Kirby, Stephanie Ferris. Royal Berkshire NHS Foundation Trust, Reading, UK

\subsection{6/bmjresp-2021-bssconf.8}

Introduction With a $2 \%$ increase in sleep referrals and impact from COVID-19, a safer and more effective way of working was required. Historically CPAP is issued face-to-face $(\mathrm{F} 2 \mathrm{~F})$, DTCC was introduced to increase patient capacity. The aim is to compare compliance and efficacy between DTCC and F2F appointments.

Method Between 12/11/20 \& 18/3/21 N=58 (44仓̊ \& 14ㅇ) patients with confirmed Obstructive Sleep Apnoea (OSA) attended DTCC. Average Oxygen Desaturation Index (ODI) 15.45 (4.47-46), age 52.1yrs (29-86), BMI 31.92 (21-55), Mean SpO2 93.81\% (81.68-96.69). Prior to DTCC patients watched demonstration video, paperwork was completed and machines pre-assigned. 10 minute appointment, patients were consented to AirView, mask size measured and post CPAP questionnaire plus brief instructions were given. First review at $\sim 4$ weeks, (use of $\geq 4 \mathrm{hrs} / \mathrm{p} / \mathrm{n}^{1}$ Weaver, TE) indicated compliance. Post ESS obtained and absolute $\Delta$ in ESS calculated to identify clinical outcomes. Data was analysis using Microsoft Excel.

Results Compliance of 50\% was achieved, $\mathrm{N}=29$ (22 $\widehat{\circ} 7$ \%), 29 patients either returned the machine, did not use or were non-compliant; (22 $\hat{\jmath} \& 7$ \% ). ESS reduced by 5.36 (50.93\%), however only 35 post CPAP questionnaires/ESS were returned. Average time for F2F appointment ( $\sim 5$ mins.) compared to DTCC ( 15 mins.). (Table 1$)$.

Discussion DTCC shows small reduction in compliance when compared to $61 \%$ from data previous local study. ${ }^{2}$ Therefore DTCC is a time efficient alternative to F2F appointments with average reduction of $\sim 30$ minutes per patient. The DTCC will aid recovery post COVID, allowing increased outpatient capacity while reducing footfall.

\section{REFERENCES}

1. Weaver TE, Grunstein RR. Adherence to continuous positive airway pressure therapy, proceedings of the american thoracic society 2008;5:173-178.

2. EJ Oakham, M Unstead, AD McGown. CPAP compliance and symptomatic benefit: a comparison of patients established on CPAP from GP or preoperative screening. Thorax 2017;2018:A1-A220

Abstract 10 Table 1 Results and key outcomes

\begin{tabular}{|c|c|c|c|c|c|c|c|}
\hline $\begin{array}{c}\text { Avg. hrs used } \\
\text { per night }\end{array}$ & AHI & Pre ESS & Compliant & $\begin{array}{c}\text { Post } \\
\text { ESS }\end{array}$ & $\begin{array}{c}\text { Absolute } \\
\Delta \text { ESS }\end{array}$ & $\begin{array}{c}\% \Delta \text { in } \\
\text { ESS }\end{array}$ & $\begin{array}{c}\text { Average time per } \\
\text { patient (mins.) }\end{array}$ \\
\hline 3.91 & 6.16 & 10.58 & $\mathrm{n} 29=50 \%$ & 5.36 & -5.58 & 48.97 & -30 \\
\hline $0-15.3$ & $0-66.3$ & 1 to 22 & $44 \AA \& 7 \%$ & 0 to 16 & $0-16$ & $0-100$ & DTCC $=15$ \\
\hline 2.99 & 11.05 & 4.96 & & 4.00 & 4.05 & 28.44 & $\mathrm{~F} 2 \mathrm{~F}=45$ \\
\hline
\end{tabular}

